\title{
LIM kinase 1 is required for insulin-dependent cell growth of osteosarcoma cell lines
}

\author{
HAI-SHAN ZHANG ${ }^{1}$, JIAN-WU ZHAO ${ }^{2}$, HONG WANG $^{3}$, HAN-YANG ZHANG ${ }^{2}$, QIU-YE JI ${ }^{3}$, \\ LING-JIE MENG ${ }^{3}$, FENG-JUAN XING ${ }^{3}$, SHU-TING YANG $^{4}$ and YAN WANG ${ }^{3}$ \\ Departments of ${ }^{1}$ Colorectal and Anal Surgery and ${ }^{2}$ Orthopaedics; ${ }^{3}$ Research Center for Gene Therapy, \\ China-Japan Union Hospital of Jilin University, Changchun, Jilin 130033; ${ }^{4}$ Department of Prosthodontics, \\ School of Stomatology, Jilin University, Changchun, Jilin 130021, P.R. China
}

Received May 9, 2013; Accepted November 6, 2013

DOI: $10.3892 / \mathrm{mmr} .2013 .1798$

\begin{abstract}
Osteosarcoma is a type of malignant bone tumor with high metastasis and poor prognosis. Previous studies have demonstrated the involvement of LIM kinase 1 (LIMK1) in the proliferation of osteosarcoma cells. LIMK1 is overexpressed in human osteosarcoma tissues and cell lines. To further study LIMK1-associated mechanisms, we used shRNA targeted to the LIMK1 gene to block its expression in the osteosarcoma cell lines MG63 and U2OS. Insulin promoted the proliferation of MG63 cells in a time- and dose-dependent manner, however, this insulin induced proliferation was significantly inhibited by transfection of shRNA targeted to the LIMK1 gene, as well as by the PI3K inhibitor LY294002, but not by the mitogen-activated protein kinase (MAPK) inhibitor PD98059. The level of cofilin phosphorylation was increased significantly following stimulation of insulin for $24 \mathrm{~h}$, indicating the activation of LIMK1. MG63 cell proliferation was also significantly inhibited by 1,25-dihydroxy vitamin D3 $\left(1,25(\mathrm{OH})_{2} \mathrm{D}_{3}\right)$ in a time-dependent manner. Furthermore, $1,25(\mathrm{OH})_{2} \mathrm{D}_{3}$ negated the inhibitory effect of LIMK1 shRNA, indicating that LIMK1 is important in the inhibitory pathway of $1,25(\mathrm{OH})_{2} \mathrm{D}_{3}$. The present study confirms that LIMK1 is important in regulating osteosarcoma cell proliferation via the insulin/PI3K/LIMK1 signaling pathway, thus the development of gene therapy for osteosarcoma targeting LIMK1 is warranted.
\end{abstract}

\section{Introduction}

Osteosarcoma is one of the most common bone tumors, particularly in teenagers. It is highly malignant with a poor

Correspondence to: Professor Yan Wang, Research Center for Gene Therapy, China-Japan Union Hospital of Jilin University, No. 126 Xiantai Street, Changchun, Jilin 130033, P.R. China E-mail:wangy01@jlu.edu.cn

Key words: human osteosarcoma cell, LIMK1, proliferation, shRNA, insulin prognosis due to its high risk of relapse and metastasis (1). Conventional treatment includes surgical resection combined with chemotherapy, which is determined based on the scope of tumor invasion. Approximately $30 \%$ of patients at early stages have distant metastasis following surgery and chemotherapy (2). With advances in molecular biology and cell biology in clinical oncology, a limited understanding of the mechanisms underlying osteosarcoma at the molecular level has been developed. The abnormal expression of certain oncogenes (e-myc, $e$-ras and $e$-fos) and anti-oncogenes (p53, Rb and pl6) has been found to be associated with this disease. This pattern of gene expression may provide a theoretical foundation of target gene selection for osteosarcoma gene therapy (3).

Actin is the major cytoskeletal protein responsible for maintaining cell shape and polarity, promoting cell migration and cytokinesis by dynamic alterations in depolymerization and repolymerization. Actin participates in various physiological and pathological processes, including phagocytosis, endocytosis, embryogenesis, organogenesis and angiogenesis (4). Recent studies have demonstrated that actin reorganization is also involved in tumor cell migration, invasion and metastasis (5-7).

Cofilin is a member of the actin depolymerization factor (ADF)/cofilin family, which is able to reinforce actin motion and assist cell movement and chemotaxis $(8,9)$. The LIM kinase 1 (LIMK1) pathway and the slingshot phosphatase pathway are two effective and important pathways involved in regulating cofilin activation. LIMK1 specifically phosphorylates cofilin and thus regulates actin filament dynamics under the control of Rac, while LIMK2 is important in regulating stress fiber and filopodia formation and accompanying actin cytoskeletal dynamics, specifically downstream of Rho and Cdc42. LIMK1 is a novel dual specificity (serine/threonine and tyrosine) kinase that contains two amino-terminal LIM domains (10). The LIMK1 gene is expressed predominantly in the brain and in developing neural tissues (11) and its deletion (microdeletion of chromosome 7q11.23) is typically associated with Williams syndrome (12). LIMK1 is activated by phosphorylation at Thr-508 (in the kinase catalytic domain) by ROCK and PAK. These activating kinases are downstream kinases of the Rho family of small GTPases, Rho, Rac and Cdc42 (13-15). LIMK1 is also able to be 
phosphorylated at Ser-323 (outside the catalytic domain) by mitogen-activated protein kinase (MAPK)-activated protein kinase-2 (MAPKAPK2), which is a kinase downstream of p38 MAPK (16).

In the present study, we silenced the LIMK1 gene using interferon RNA in the cultured human osteosarcoma cell lines U2OS and MG63, and studied the effect and mechanisms of human osteosarcoma cell proliferation following LIMK1 knockdown.

\section{Materials and methods}

Tissue samples and cell culture. The human osteosarcoma cell lines U2OS and MG63 (purchased from the Institute of Biochemistry and Cell Biology, Shanghai Institutes for Biological Sciences, Chinese Academy of Sciences, Shanghai, China) were cultured in high glucose Dulbecco's modified Eagle's medium (H-DMEM; Gibco-BRL Carlsbad, CA, USA) containing $10 \%$ fetal calf serum. Human fetal osteoblastic (hFOB) 1.19 cells (donated by the Pathology Laboratory of Jilin University, Changchun, Jilin, China) were cultured in DMEM-F12 (Gibco-BRL) supplemented with $10 \%$ fetal calf serum. All three types of cells were incubated at $37^{\circ} \mathrm{C}$, saturated humidity and $5 \% \mathrm{CO}_{2}$.

Tumor samples from a total of 6 patients were collected intraoperatively and stored at $-80^{\circ} \mathrm{C}$ with written consent obtained. The present study was approved by the Institutional Review Board of Jilin University and informed consent was obtained from the patients/patient's families.

Immunohistochemical and hematoxylin and eosin $(H E)$ staining. Tumor tissue sections were incubated with $3 \% \mathrm{H}_{2} \mathrm{O}_{2}$ to inactivate endogenous peroxidase followed by deparaffination and rehydration. The antigen was restored with $3 \%$ proteinase $\mathrm{K}$, followed by washing with phosphate-buffered saline (PBS) and blocking with $10 \%$ goat serum for $1 \mathrm{~h}$ at room temperature. The sections were then incubated for $1 \mathrm{~h}$ at room temperature with a mouse $\mathrm{mAb}$ targeting $\beta$-actin (1:500; Santa Cruz Biotechnology, Inc., Santa Cruz, CA, USA) or rabbit pAb to LIMK1, p-LIMK1, cofilin or p-cofilin (1:100, Santa Cruz Biotechnology, Inc.) to detect tumor cells. Biotinylated rabbit anti-mouse immunoglobulin diluted 1:100 in $3 \%$ normal goat serum was applied for $1 \mathrm{~h}$ and followed with peroxidase-conjugated horseradish streptavidin-biotin complex for $10 \mathrm{~min}$. Reaction sites were visualized using diaminobenzidine as the chromogen and nuclei were counterstained with hematoxylin. Paraffin-embedded sections were dehydrated, mounted with neutral gum and observed under a light microscope (Olympus, Tokyo, Japan).

Immunoprecipitation and western blot analysis. Human osteosarcoma cells, U2OS and MG63, and human osteoblast cells, HFOB1.19, were lysed with lysis buffer $(150 \mathrm{mM}$ of $\mathrm{NaCl}$, $1 \%$ Nonidet P-40, $50 \mathrm{mM}$ of Tris- $\mathrm{HCl}, \mathrm{pH} 8.0$ and $20 \mu \mathrm{M}$ of PMSF) at $4^{\circ} \mathrm{C}$ for $30 \mathrm{~min}$ and centrifuged at $12,000 \mathrm{x} \mathrm{g}$ at $4^{\circ} \mathrm{C}$ for $15 \mathrm{~min}$. The supernatant was stored at $-70^{\circ} \mathrm{C}$. Equal amounts of protein (100 ng), $15 \mu \mathrm{l}$ of protein A agarose beads and $1 \mu 1$ of anti-LIMK1 antibody (Santa Cruz Biotechnology, Inc.) were added to the tubes and rotated overnight at $4^{\circ} \mathrm{C}$. The agarose-antibody-antigen complexes were collected by centrifugation (20 sec at $12,000 \mathrm{x} \mathrm{g}$ ). The supernatant was carefully removed and the complexes were washed twice with lysis buffer. The pellet was resuspended in gel-loading buffer and the protein was denatured by boiling for $5 \mathrm{~min}$. Protein A agarose beads were removed by centrifugation at $12,000 \mathrm{x} \mathrm{g}$ for $20 \mathrm{sec}$ and the supernatant was transferred to a fresh tube. The proteins were separated by SDS-PAGE and analyzed by immunoblotting analysis, as described previously (17), using primary antibodies against LIMK1, P(T508)-LIMK1, cofilin and p-cofilin (1:500; Santa Cruz Biotechnology, Inc.). Immunodetection was accomplished using a HRP-conjugated goat anti-rabbit secondary antibody (1:1,000; Bioworld Technology Co, Ltd., St. Louis Park, MN, USA) and protein bands were developed with an ECL Chemiluminescent Substrate Reagent kit (Invitrogen Life Technologies, Carlsbad, CA, USA) and analyzed by Image J Software (National Institutes of Health, Bethesda, MD, USA).

Knockdown of LIMK1. To assess the effect of LIMK1 knockdown on insulin-induced cell proliferation, we generated an shRNA construct using the pSUPER vector (Oligo Engine, Seattle, WA, USA), as described previously $(18,19)$. The 19-base targeting sequences used in the present study were as follows: 5'-GCTGGAACAATGGCTAGAA-3' (human LIMK1). As a control, we used a nontargeting sequence, 5'-TCTTCCCCCAAGAAAGATA-3', which does not exist in the human genome. MG63 cells were plated in $100 \mathrm{~mm}$ dishes $\left(1.5 \times 10^{6}\right.$ cells/dish) and cultured for $24 \mathrm{~h}$ followed by transfection with pSUPER-LIMK1 or the control pSUPER vector. Transfected cells were cultured for $24 \mathrm{~h}$ prior to being transferred into 96-well chamber slides at $5 \times 10^{3}$ cells/well. The cells were continuously cultured for $16 \mathrm{~h}$ followed by serum starvation for $4 \mathrm{~h}$ and then cultured with or without $1 \mu \mathrm{g} / \mathrm{ml}$ of insulin for $24 \mathrm{~h}$.

Cell proliferation assay. MG63 or transfected MG63 (pSUPER-LIMK1-MG63) cells were seeded into 96-well plates. After achieving $70 \%$ confluence, the cells were suspended in $100 \mu \mathrm{l}$ of serum-free medium. After $24 \mathrm{~h}$, insulin (1 $\mu \mathrm{g} / \mathrm{ml}$; Sigma, St. Louis, MO, USA) or 1,25-dihydroxy vitamin D3 $\left(1,25(\mathrm{OH})_{2} \mathrm{D}_{3} ; 10^{-7} \mathrm{~mol} / \mathrm{l}\right.$; Sigma) was added into each well. The Cell Counting kit-8 (CCK-8, Dojindo Laboratories, Kumamoto, Japan) was used to assess cell proliferation at 24,48 and $72 \mathrm{~h}$. To study the effect of inhibitors, cells were incubated with $20 \mathrm{mM}$ of PD98059, a selective MEK1 inhibitor (Sigma), or $10 \mu \mathrm{M}$ of LY294002, a potent inhibitor for PI3K (Sigma). Cells were exposed to these inhibitors in serum-free medium at $37^{\circ} \mathrm{C}$ for $1 \mathrm{~h}$, followed by the addition of $1 \mu \mathrm{g} / \mathrm{ml}$ of insulin. The control group was treated with H-DMEM as a standard solution. Cells in the culture plates were incubated at $37^{\circ} \mathrm{C}$ with $5 \% \mathrm{CO}_{2}$ and $95 \%$ humidity. After $24 \mathrm{~h}$, the optical density of the wells was read at $450 \mathrm{~nm}$. The CCK-8 (Dojindo Laboratories) reagent $(10 \mu \mathrm{l})$ was added into each well and incubated at $37^{\circ} \mathrm{C}$ for $2 \mathrm{~h}$ and the optical density was read again at $450 \mathrm{~nm}$. The cell proliferation was calculated according to the manufacturer's instructions.

Statistical analysis. All data are presented as the mean \pm standard deviation (mean $\pm \mathrm{SD}$ ). Statistical analysis was performed 
using one-way ANOVA (including Newman-Keuls multiple comparison test) and statistical analysis software Prism 4 (GraphPad Software, Inc., La Jolla, CA, USA). P<0.05 was considered to indicate a statistically significant difference.

\section{Results}

Expression of LIMK1, p-LIMK1, cofilin and p-cofilin in human osteosarcoma cells. Human osteosarcomatous tissues were analyzed by HE staining and intensity immunohistochemistry was performed using a specific antibody to recognize the expression of LIMK1/p-LIMK1 and cofilin/P-cofilin in human osteosarcoma tissues. We demonstrated that tumor cells were distributed in a diffuse pattern or formed cancer nests. The size and the degree of differentiation of the cells varied. The cells demonstrated large heteromorphic anachromasis and karyokinesis and a high nucleo-cytoplasmic ratio (Fig. 1A and B). The expression of cofilin/p-cofilin (Fig. 1C and D) and LIMK1/p-LIMK1 (Fig. 1E and F) in tumor parenchyma was clearly higher than that in the mesenchyme, indicating that LIMK1 and cofilin were overexpressed in osteosarcomatous parenchyma. This result was confirmed by western blot analysis, which demonstrated that the expression levels of LIMK1 in U2OS and MG63 cells were almost 2-fold of that in hFOB1.19 cells (Fig. 2). These data indicated that the overexpression of LIMK1 may be associated with osteosarcoma biological activity.

Effect of LIMK1 in insulin and 1,25(OH $)_{2} \mathrm{D}_{3}$ mediated proliferation of human osteosarcoma cells. Insulin exerts, via the insulin receptor $\alpha$, a wide range of biological responses affecting glucose, lipid and protein metabolism as well as cell proliferation and survival $(20,21)$. The effect of insulin on the proliferation of MG63 cells was assessed. The results demonstrated that insulin dose-dependently promoted the proliferation of MG63, with an effective concentration between 0.5 to $10 \mu \mathrm{g} / \mathrm{ml}$ (Fig. 3A). MG63 cells were then treated with $1 \mu \mathrm{g} / \mathrm{ml}$ of insulin for $0,24,48$ and $72 \mathrm{~h}$ (Fig. 3B). The results demonstrated that the insulin-induced cell proliferation increased with time and the effect of insulin was predominantly robust at $24 \mathrm{~h}$.

We also studied the possible mechanisms responsible for insulin-induced osteosarcoma cell proliferation. Osteosarcoma cells were pretreated with the PI3K pathway inhibitor LY294002 $(10 \mu \mathrm{M})$ or the MAPK pathway inhibitor PD98059 $(20 \mu \mathrm{M})$ for $1 \mathrm{~h}$ prior to $24 \mathrm{~h}$ incubation with insulin. The results demonstrated that PD98059 had no impact on insulin-induced cell proliferation, whereas LY294002 significantly inhibited insulin-induced cell proliferation (Fig. 3C), indicating that insulin-induced cell proliferation may be associated with the PI3K pathway, but not the MAPK pathway.

LIMK1 activation leads to the phosphorylation and deactivation of cofilin, which is a specific substrate of LIMK1 (22). Thus, we examined the expression and activation of cofilin in human osteosarcoma cells by western blotting. After MG63 cells were stimulated by insulin at various concentrations for $24 \mathrm{~h}$, the expression of $\mathrm{p}$-cofilin and p-LIMK1 was significantly increased compared with
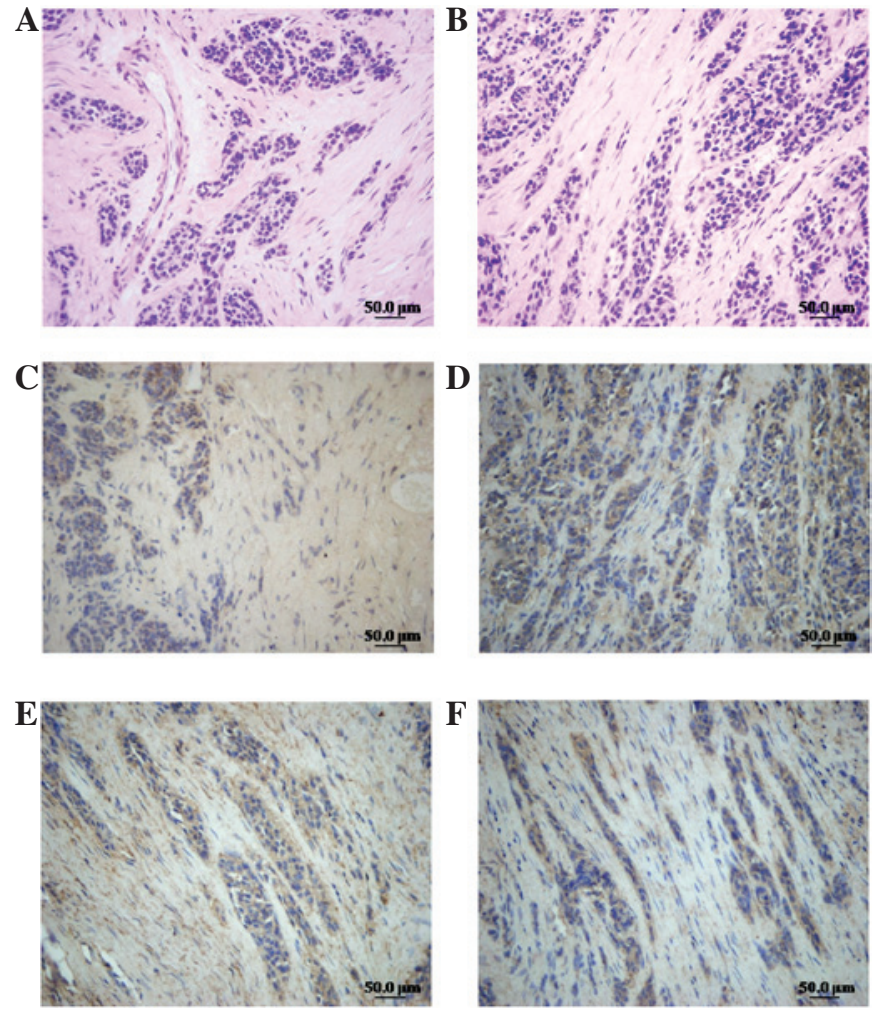

Figure 1. LIMK1/p-LIMK1 and cofilin/p-cofilin are differentially expressed in human osteosarcoma tissues. (A and B) HE staining of human osteosarcomatous tissues (magnification, $\mathrm{x} 400$ ). (C and D) IHC staining using antibodies to cofilin/p-cofilin and (E and F) LIMK1/p-LIMK1 in human osteosarcoma tissues (magnification, x400). Scale bar, $50 \mu \mathrm{m}$. LIMK1, LIM kinase 1; IHC, immunohistochemistry; HE, hematoxylin and eosin.

A
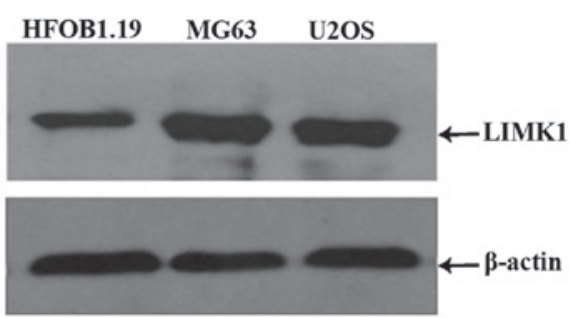

B

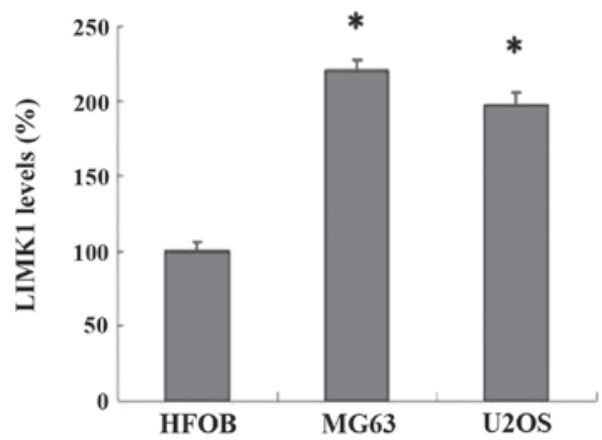

Figure 2. Expression of LIMK1 in human osteosarcoma cells and human osteoblast cells. (A) Western blotting was performed to detect the levels of LIMK1. The expression of LIMK1 in MG63 and U2OS cells was higher than HFOB. (B) Quantification of the proteins. $n=6$; ${ }^{*} \mathrm{P}<0.05$. LIMK1, LIM kinase 1; HFOB, human fetal osteoblastic cells.

the control group. Pretreatment of cells with LY294002 significantly inhibited the insulin-induced increase of p-cofilin and p-LIMK1 expression (Fig. 4). By contrast, 
A

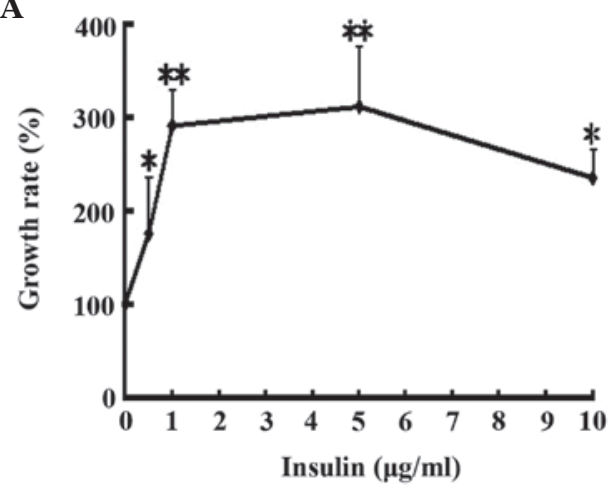

B

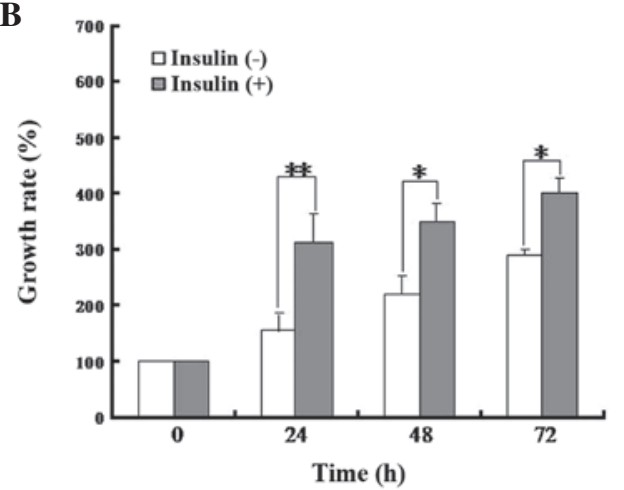

C

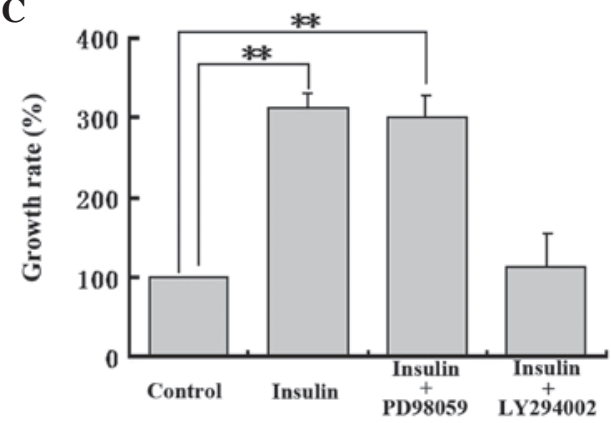

Figure 3. Effect of insulin on the proliferation of human osteosarcoma cells. (A) Serum-starved MG63 cells were stimulated with different concentrations of insulin. Cells were incubated with the CCK- 8 kit, the OD values were measured at 450 nm. $n=6 ;{ }^{*} \mathrm{P}<0.05,{ }^{* *} \mathrm{P}<0.01$. (B) Serum-starved MG63 cells were stimulated with $1 \mu \mathrm{g} / \mathrm{ml}$ of insulin for the indicated times. The control group was treated without insulin stimulation. Cells were incubated with the CCK- 8 kit and the OD values were measured at $450 \mathrm{~nm} . \mathrm{n}=6$; ${ }^{*} \mathrm{P}<0.05,{ }^{* *} \mathrm{P}<0.01$. (C) Effect of insulin on cell proliferation in human osteosarcoma cells with signal inhibitors. MG63 cells were incubated with $20 \mathrm{mM}$ of PD98059 or $10 \mu \mathrm{M}$ of LY294002 in serum-free medium at $37^{\circ} \mathrm{C}$ for $1 \mathrm{~h}$ and then stimulated with $1 \mu \mathrm{g} / \mathrm{ml}$ of insulin; the control group was treated with a standard solution. Cells were incubated with the CCK- 8 kit, the OD values were measured in $450 \mathrm{~nm}\left(\mathrm{n}=6 ;{ }^{* *} \mathrm{P}<0.01\right)$. CCK-8, cell counting kit-8; OD, optical density.

cells pre-treated with PD98059 presented no alterations (data not shown).

Our data suggested that insulin-induced human osteosarcoma cell proliferation was associated with the LIMK1/cofilin signaling pathway, which is regulated by PI3K. To determine the role of LIMK1 in this pathway, we constructed an shRNA vector targeting LIMK1 (pSUPER-LIMK1). Western blotting demonstrated that MG63 cells transfected with the LIMK1 shRNA expressed little endogenous LIMK1 compared with cells transfected with control shRNA (Fig. 5A), indicating that the shRNA vector targeting LIMK1 (pSUPER-LIMK1) was constructed successfully. Furthermore, the LIMK1
A

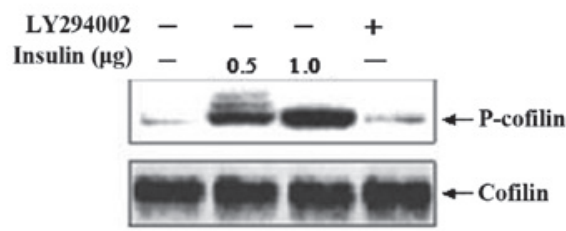

B

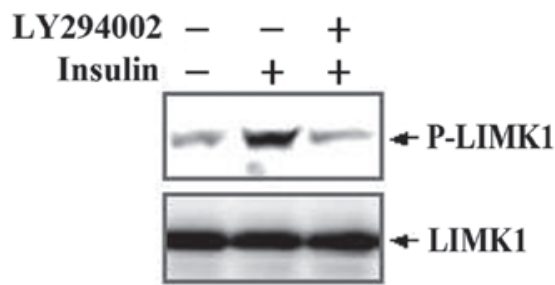

Figure 4. Changes in p-cofilin/p-LIMK1 following stimulation with insulin for $24 \mathrm{~h}$ in human osteosarcoma cells. (A) Phosphorylation of cofilin by insulin. Serum-starved MG63 cells were preincubated in LY294002 (lane 4) and then stimulated with 0.5 or $1 \mu \mathrm{g}$ of insulin. Changes in levels of p-cofilin in lysates were immunoblotted with anti-p-cofilin and anti-cofilin antibodies. (B) Phosphorylation of LIMK1 by insulin. Serum-starved MG63 cells were preincubated in LY294002 and then stimulated with insulin. Lysates of MG63 cells were immunoprecipitated with anti-LIMK1 antibody. p-LIMK1 in lysates were immunoblotted with anti-p-LIMK1 and anti-LIMK1 antibodies. LIMK1, LIM kinase 1.

A

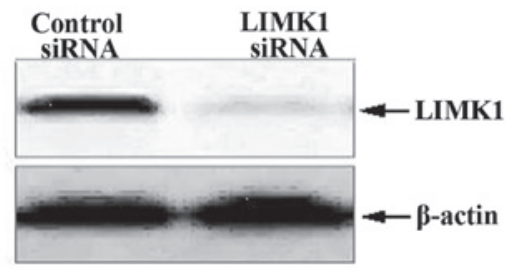

B

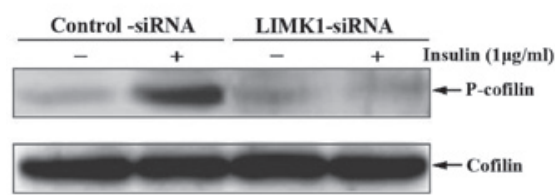

C

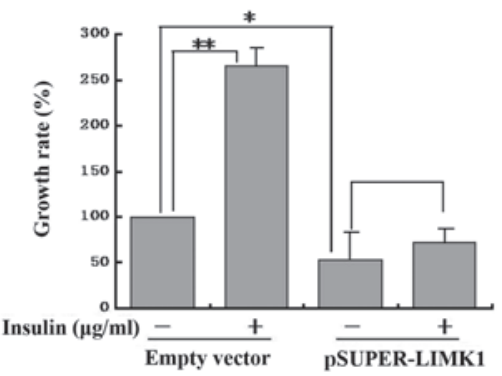

Figure 5. LIMK1 is critical for insulin-induced cofilin phosphorylation. (A) The suppression of LIMK1 expression by shRNA. MG63 cells were transfected with LIMK1 shRNA (pSUPER-LIMK1) or a control shRNA vector. Expression of endogenous LIMK1 and actin was analyzed by immunoblotting with anti-LIMK1 and anti- $\beta$-actin antibodies. (B) Blocking LIMK1 expression suppresses insulin-induced cofilin phosphorylation. Phosphorylation of cofilin by insulin was inhibited by LIMK1 shRNA. Serum-starved MG63 cells were transfected with LIMK1 shRNA and then stimulated with $1 \mu \mathrm{g} / \mathrm{ml}$ of insulin. P-cofilin/cofilin in lysates were immunoblotted with anti-p-cofilin and anti-cofilin antibodies. (C) MG63 cells were transfected with LIMK1 shRNA and then stimulated with $1 \mu \mathrm{g} / \mathrm{ml}$ of insulin. The control group was transfected with an empty plasmid. Cell proliferation was detected with the CCK- 8 kit, the OD values were measured in $450 \mathrm{~nm}$ $(\mathrm{n}=6) .{ }^{*} \mathrm{P}<0.05,{ }^{* *} \mathrm{P}<0.01$. CCK-8, cell counting kit-8; OD, optical density; LIMK1, LIM kinase 1; pSUPER-LIMK1, shRNA vector targeting LIMK1. 


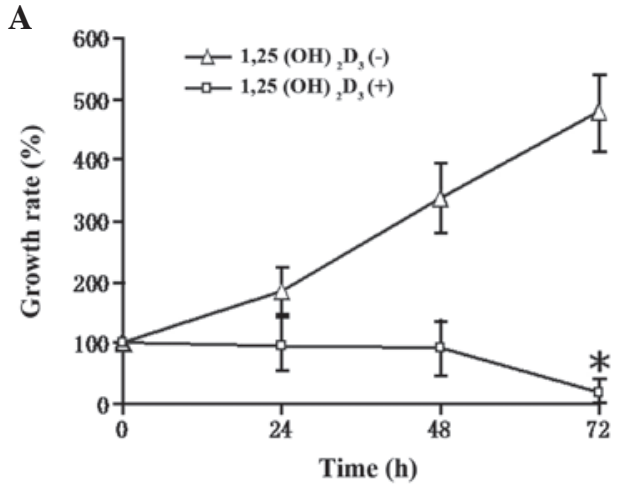

B

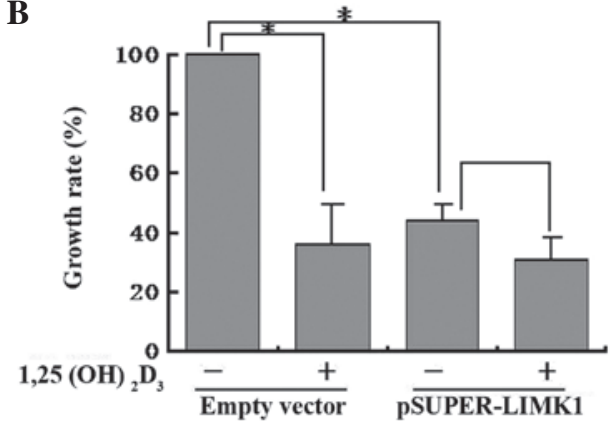

C

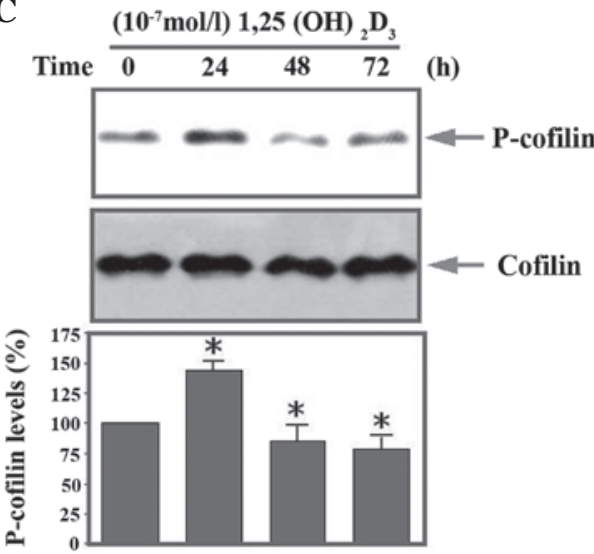

Figure 6. Effect of LIMK1 in $1,25(\mathrm{OH})_{2} \mathrm{D}_{3}$ mediated proliferation of human osteosarcoma cells. (A) Serum-starved MG63 cells were stimulated with $1,25(\mathrm{OH})_{2} \mathrm{D}_{3}\left(10^{-7} \mathrm{~mol} / \mathrm{l}\right)$ for the indicated times. Cell proliferation was detected with the CCK- 8 kit, the OD values were measured at $450 \mathrm{~nm}$. (B) MG63 cells were transfected with LIMK1 shRNA and then stimulated with $1,25(\mathrm{OH})_{2} \mathrm{D}_{3}$. The control group was transfected with an empty vector. Cell proliferation was detected with the CCK- 8 kit, the OD values were measured at $450 \mathrm{~nm}$. (C) Western blot analysis of the expression of p-cofilin at various times following $1,25(\mathrm{OH})_{2} \mathrm{D}_{3}$ stimulation. Serum-starved MG63 cells were stimulated with $1,25(\mathrm{OH})_{2} \mathrm{D}_{3}$ for the indicated times. Cell lysates were immunoblotted with anti-p-cofilin and anti-cofilin antibodies. The bottom panels show the relative p-cofilin levels. LIMK1, LIM kinase $1 ; 1,25(\mathrm{OH})_{2} \mathrm{D}_{3}$, 1,25-dihydroxy vitamin D3; CCK-8, cell counting kit-8; OD, optical density.

shRNA, but not the control shRNA, blocked insulin-induced cofilin phosphorylation (Fig. 5B). After the LIMK1 gene was silenced by transfection of pSUPER-LIMK1, there was a significant decrease in cell proliferation and insulin-induced proliferation was completely inhibited (Fig. 5C), indicating that LIMK1 was essential in regulating the basic and insulin-induced proliferation of MG63 human osteosarcoma cells.

Additionally, we demonstrated that $1,25(\mathrm{OH})_{2} \mathrm{D}_{3}$, at a concentration of $10^{-7} \mathrm{~mol} / \mathrm{l}$, inhibited human osteosarcoma cell proliferation in a time-dependent manner (Fig. 6A). Transfection of pSUPER-LIMK1 plasmids led to significant inhibition of osteosarcoma cell proliferation. However, after $1,25(\mathrm{OH})_{2} \mathrm{D}_{3}$ was added, no further inhibition was observed indicating that LIMK1 is important in the inhibition of proliferation by $1,25(\mathrm{OH})_{2} \mathrm{D}_{3}$ (Fig. 6B). Western blot analysis demonstrated that $\mathrm{p}$-cofilin expression increased transiently at $24 \mathrm{~h}$, followed by a decrease from 48 to $72 \mathrm{~h}$ following $1,25(\mathrm{OH})_{2} \mathrm{D}_{3}$ treatment (Fig. $6 \mathrm{C}$ ). The activity of cofilin is reversibly regulated by phosphorylation and dephosphorylation at Ser-3, with the phosphorylated form being inactive. LIMK phosphorylates cofilin at Ser-3 and thereby inhibits the actin filament disrupting the activity of cofilin. The inactive Ser-3-phosphorylated cofilin (p-cofilin) is dephosphorylated and reactivated by slingshot ( $\mathrm{SSH}$ ) family protein phosphatases. Previous studies have demonstrated that slingshot and LIMK spatially and temporally regulate the expression of cofilin $(23,24)$. Thus, we hypothesized that the inhibitory effect of $1,25(\mathrm{OH})_{2} \mathrm{D}_{3}$ on cell proliferation may be associated with LIMK, slingshot or other related proteins. However, further studies are needed to examine this link.

\section{Discussion}

LIMK1, one of the LIMK proteins, is a serine/threonine protein kinase that deactivates cofilin by phosphorylation, thus participating in the rearrangement of the actin cytoskeleton. Activation of LIMK1 is regulated by multiple mechanisms and is important in extracellular stimulation and cytoskeleton stability (25). Recent studies have demonstrated that LIMK1 is overexpressed and highly active in cells and tissues of certain malignant tumors, including prostatic cancer and breast cancer (26), thus LIMK1 may be one of the key molecules that stimulates tumor cell invasion and metastasis, or possibly a new 'oncogene' (9). In the present study, LIMK1 and p-LIMK1 expression in tumor parenchyma cells are significantly higher than that in mesenchymal cells. Furthermore, compared with human osteoblast cells HFOB 1.19, expression of LIMK1 protein in human osteosarcoma cells U2OS and MG63 was markedly higher, suggesting that overexpression of the LIMK1 protein in human osteosarcoma cells may have a connection with the biological characteristics of osteosarcoma.

Insulin is a hormone with various biological effects, including the regulation of cell proliferation. Two major pathways have been described in insulin signal transduction, one is the PI3K pathway, the other is the MAPK pathway. In the present study, insulin robustly enhanced MG63 cell proliferation in a time and concentration-dependent manner. After cells were pretreated with the PI3K pathway inhibitor LY294002, insulin-induced MG63 cell proliferation was inhibited. By contrast, the MAPK pathway inhibitor PD98059 had little effect, indicating that insulin-induced MG63 cell proliferation primarily relies on the PI3K pathway.

In the present study, we detected changes in cofilin protein expression and activity in human osteosarcoma cells stimulated by insulin at various concentrations for $24 \mathrm{~h}$. Compared with the control group, p-cofilin expression was significantly increased, which indicated that insulin activates cofilin-related signaling pathways. LIMK1 is important in cofilin activation, thus cofilin phosphorylation, to a certain extent, is associated 
with LIMK1 activation. However, insulin-induced activation of cofilin was inhibited by LY294002, suggesting PI3K is involved in this process.

We then transfected the pSUPER-LIMK1 plasmid into MG63 cells to block transcription of the LIMK1 gene. Cell proliferation was inhibited by blocking LIMK1 gene expression, furthermore, insulin-induced cell proliferation was eradicated as well. These data suggest that the expression of LIMK1 and the activation of the insulin/LIMK1 pathway are crucial in regulating MG63 cell proliferation.

The hormone variant of vitamin $\mathrm{D} 3,1,25(\mathrm{OH})_{2} \mathrm{D}_{3}$, regulates the expression of genes through the interaction between the specificity receptor vitamin D receptor (VDR), similarly to other steroid hormones. It is also important in inhibiting tumor cell proliferation and promoting tumor cell differentiation (27). Prior studies have demonstrated that $1,25(\mathrm{OH})_{2} \mathrm{D}_{3}$ inhibits the proliferation of numerous tumors and synergistically promotes apoptotic death of tumor cells in combination with other anticancer drugs $(28,29)$. However, the signaling transduction mechanisms by which $1,25(\mathrm{OH})_{2} \mathrm{D}_{3}$ inhibits tumor cell proliferation are not clear. Using western blotting we demonstrated that $\mathrm{p}$-cofilin expression significantly increased following stimulation with $10^{-7} \mathrm{~mol} / \mathrm{l}$ of $1,25(\mathrm{OH})_{2} \mathrm{D}_{3}$ for $24 \mathrm{~h}$. The proliferation of human osteosarcoma MG63 cells was significantly inhibited after cells were stimulated with $10^{-7} \mathrm{~mol} / \mathrm{l}$ of $1,25(\mathrm{OH})_{2} \mathrm{D}_{3}$. Cell proliferation was also significantly inhibited after the plasmid pSUPER-LIMK1 was transfected into human osteosarcoma cells, however, there was no apparent further inhibition following the addition of $1,25(\mathrm{OH})_{2} \mathrm{D}_{3}$, indicating that LIMK 1 and $1,25(\mathrm{OH})_{2} \mathrm{D}_{3}$ may share the same pathway in inhibiting the proliferation of human osteosarcoma cells.

In summary, LIMK1 and activation of the insulin/PI3K/LIMK1 signaling pathway have major effects on human osteosarcoma cell proliferation. The present study provides new insight into LIMK1-regulated osteosarcoma genesis and development.

\section{Acknowledgements}

This study was supported by the National Natural Science Foundation of China (no. 81172000).

\section{References}

1. Picci P: Osteosarcoma (osteogenic sarcoma). Orphamet J Rare Dis 2: 623-637, 2007.

2. Yamazaki D, Kurisu S and Takenawa T: Regulation of cancer cell motility through actin reorganization. Cancer Sci 96: 379-386, 2005.

3. Gamberi G, Benassi MS, Bohling T, et al: C-myc and c-fos in human osteosarcoma, prognostic value of mRNA and protein expression. Oncology 55: 556-563, 1998.

4. Wang Y, Shibasaki F and Mizuno K: Calcium signal-induced cofilin dephosphorylation is mediated by Slingshot via calcineurin. J Biol Chem 280: 12683-12689, 2005.

5. Tsai WC, Jin JS, Yu JC, et al: CD10, actin, and vimentin expression in breast phyllodes tumors correlates with tumor grades of the WHO grading system. Int J Surg Pathol 14: 127-131, 2006.

6. Sebzda T, Saleh Y, Malicka-Blaszkiewicz M, et al: Actin content and actin polymerization in hepatoma Morris 5123 tumor bearing rats after treatment with cysteine protease inhibitor and vitamin E. J Exp Ther Oncol 5: 23-29, 2005.
7. Amsellem V, Kryszke MH, Hervy M, et al: The actin cytoskeleton-associated protein zyxin acts as a tumor suppressor in Ewing tumor cells. Exp Cell Res 304: 443-456, 2005.

8. Pavlov D, Muhlrad A, Cooper J, et al: Actin filament severing by cofilin. J Mol Biol 365: 1350-1358, 2007.

9. Huang TY, DerMardirossian C and Bokoch GM: Cofilin phosphatases and regulation of actin dynamics. Curr Opin Cell Biol 18: 26-31, 2006.

10. Okano I, Hiraoka J, Otera $\mathrm{H}$, et al: Identification and characterization of a novel family of serine/threonine kinases containing two N-terminal LIM motifs. J Biol Chem 270: 31321-31330, 1995.

11. Bernard O, Geniatsus S, Kannourakis G and Dringen R: Kiz-1, a protein with LIM zinc finger and kinase domains, is expressed mainly in neurons. Cell Growth Differ 5: 1159-1171, 1994.

12. Wouters CH, Meijers-Heijboer HJ, Eussen BJ, et al: Deletions at chromosome regions $7 \mathrm{q} 11.23$ and $7 \mathrm{q} 36$ in a patient with Williams syndrome. Am J Med Genet 102: 261-265, 2001.

13. Edwards DC, Sanders LC, Bokoch GM and Gill GN: Activation of LIM-kinase by Pak1 couples Rac/Cdc42 GTPase signalling to actin cytoskeletal dynamics. Nat Cell Biol 1: 253-259, 1999.

14. Maekawa M, Ishizaki T, Boku S, et al: Signaling from Rho to the actin cytoskeleton through protein kinases ROCK and LIM-kinase. Science 285: 895-898, 1999.

15. Ohashi K, Nagata K, Maekawa M, et al: Rho-associated kinase ROCK activates LIM-kinase 1 by phosphorylation at threonine 508 within the activation loop. J Biol Chem 275: 3577-3582, 2000.

16. Kobayashi M, Nishita M, Mishima T, Ohashi K and Mizuno K: MAPKAPK-2-mediated LIM-kinase activation is critical for VEGF-induced actin remodeling and cell migration. EMBO J 25: 713-726, 2006.

17. Okano I, Hiraoka J, Otera H, et al: Identification and characterization of a novel family of serine/threonine kinases containing two N-terminal LIM motifs. J Biol Chem 270: 31321-31330, 1995.

18. Brummelkamp TR, Bernards R and Agami R: A system for stable expression of short interfering RNAs in mammalian cells. Science 296: 550-553, 2002.

19. Takemura M, Mishima T, Wang Y, et al: $\mathrm{Ca} 2+/$ calmodulin-dependent protein kinase IV-mediated LIM kinase activation is critical for calcium signal-induced neurite outgrowth. J Biol Chem 284: 28554-28562, 2009.

20. Cheatham B and Kahn CR: Insulin action and the insulin signaling network. Endocr Rev 16: 117-142, 1995.

21. White MF: The insulin signalling system and the IRS proteins. Diabetologia 40: S2-S17, 1997.

22. Wilson C, Vereshchagina N, Reynolds B, et al : Extracellular and subcellular regulation of the PI3K/Akt cassette: new mechanisms for controlling insulin and growth factor signalling. Biochem Soc Trans 35: 219-221, 2007.

23. Nishita M, Tomizawa C, Yamamoto M, et al: Spatial and temporal regulation of cofilin activity by LIM kinase and Slingshot is critical for directional cell migration. J Cell Biol 171: 349-359, 2005.

24. Soosairajah J, Maiti S, Wiggan O, et al: Interplay between components of a novel LIM kinase-slingshot phosphatase complex regulates cofilin. EMBO J 24: 473-486, 2005.

25. Takahashi H, Funakoshi $\mathrm{H}$ and Nakamura T: LIM-kinase as a regulator of actin dynamics in spermatogenesis. Cytogenet Genome Res 103: 290-298, 2003.

26. Davila M, Frost AR, Grizzle WE and Chakrabarti R: LIM kinase 1 is essential for the invasive growth of prostate epithelial cells: implications in prostate cancer. J Biol Chem 278: 36868-36875, 2003.

27. Makishima M and Honma Y: Ethacrynic acid and 1 alpha, 25-dihydroxyvitamin D3 cooperatively inhibit proliferation and induce differentiation of human myeloid leukemia cells. Leuk Res 20: 781-789, 1996.

28. Kawa S, Nikaido T, Aoki Y, et al: Vitamin D analogues up-regulate p21 and p27 during growth inhibition of pancreatic cancer cell lines. Br J Cancer 76: 884-889, 1997.

29. Wilentz RE, Iacobuzio-Donahue CA, Argani P, et al: Loss of expression of Dpc4 in pancreatic intraepithelial neoplasia, evidence that DPC4 inactivation occurs late in neoplastic progression. Cancer Res 60: 2002-2006, 2000. 